\title{
Anion Pairs Template a Trigonal Prism with Disilver Vertices
}

\author{
John P. Carpenter, ${ }^{\ddagger}$ Charlie T. McTernan, ${ }^{\ddagger}$ Tanya K. Ronson, and Jonathan R. Nitschke* \\ Department of Chemistry, University of Cambridge, Lensfield Road, Cambridge CB2 1EW, U.K.
}

Supporting Information Placeholder

\begin{abstract}
Here we describe the formation of a trigonal prismatic cage, utilizing 2-formyl-1,8-naphthyridine subcomponents to bind pairs of silver(I) ions in close proximity. This cage is the first example of a new class of subcomponent selfassembled polyhedral structures having bimetallic vertices, as opposed to the single metal centers that typically serve as structural elements within such cages. Our new cage self-assembles around a pair of anionic templates, which are shown by crystallographic and solution-phase data to bind within the central cavity of the structure. Many different anions serve as competent templates and guests. Elongated dianions, such as the strong oxidizing agent peroxysulfate, also serve to template and bind within the cavity of the prism. The principle of using subcomponents that have more than one spatially close, but non-chelating, binding site may thus allow access to other higher-order structures with multi-metallic vertices.
\end{abstract}

Self-assembly allows the efficient construction of complex architectures from relatively simple components. Polyhedral metal-organic cages are a class of such architectures that have been the focus of intense recent work. ${ }^{1-3}$

Much effort has gone into the design of multi-topic organic ligands for these cages. The symmetries and connection properties of these ligands and their metal-ion partners (typi-

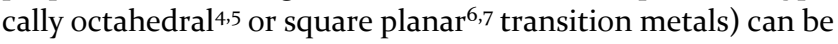
used to create structures with diverse functions. ${ }^{8,9}$

A key feature of these cages is the presence of an internal cavity of well-defined shape, size, and charge density. These cavities may offer chemical environments distinct from that of the bulk solvent. They have thus found applications in areas such as molecular sequestration, ${ }^{10-12}$ chiral sensing, ${ }^{13}$ and the stabilization of reactive species $^{14}$ and reaction intermediates. ${ }^{15,16}$

Novel architectures and functions can be obtained through the use of flexible organic building blocks. ${ }^{17,18}$ Many systems that incorporate such species form unexpected and often structurally complex architectures, including a range of intricate cages and grids, ${ }^{19-21}$ which have been used for catalysis, $^{22}$ guest binding ${ }^{23}$ and molecular knot formation. ${ }^{24,25}$

We hypothesized that novel coordination motifs could be used in an analogous way to these flexible ligands. Complexes that contain two metal ions in close proximity are an area of active interest, particularly in catalysis. ${ }^{26,27}$ Such bimetallic complexes can adopt a variety of configurations, displaying features such as anion inclusion, ${ }^{28}$ the incorporation of different numbers of ligands, ${ }^{29}$ or metal-metal bonding. ${ }^{30}$

We reasoned that the non-converging coordination vectors of commercially-available 2-formyl-1,8-naphthyridine, , $^{31,32}$ along with the flexible coordination sphere of silver(I),33-35 could lead to the formation of architectures with unprecedented geometries. Here we report the preparation of ${ }^{A} g_{12}^{I} \mathrm{~L}_{6}$ trigonal prism using a subcomponent self-assembly approach. ${ }^{36,37}$ This structure makes use of bimetallic units to define the vertices of a three-dimensional metal-organic structure, opening the door to further investigation of new polyhedral architectures in this class of compounds. It is also the first example of this type of prismatoid constructed with three-fold symmetric building blocks, to the best of our knowledge.

The reaction of tris (4-aminophenyl)amine $\mathbf{A}$ ( 6 equiv.) and 2-formyl-1,8-naphthyridine B (12 equiv.) with silver(I) perchlorate $\left(\mathrm{ClO}_{4}^{-}, 12\right.$ equiv.) yielded $\mathrm{Ag}_{12}^{\mathrm{I}} \mathrm{L}_{6}$ cage 1 (Figure 1 ), whose composition was confirmed by both ESI- and HR-MS (Figures S8 and S9). ' $\mathrm{H}$ NMR spectroscopy revealed 28 signals, consistent with a distinct environment for each ligand arm, and with two of the phenyl rings undergoing rapid rotation on the NMR timescale (Figure 2c).

Further analysis by diffusion ordered spectroscopy (DOSY) supported the formation of a single product structure in solution, with an observed diffusion coefficient of $4.8 \times 10^{-6}$ $\mathrm{cm}^{2} \mathrm{~s}^{-1}$, corresponding to a hydrodynamic radius of $12 \AA$ (Figure 2c).

Vapor diffusion of diisopropyl ether $\left(\mathrm{iPr}_{2} \mathrm{O}\right)$ into an acetonitrile solution of $\mathbf{1}$ provided crystals suitable for analysis by $\mathrm{X}$-ray diffraction. The cationic portion of $\mathbf{1}$ was revealed to have a twisted trigonal prismatic structure (Figure 1c-d) with a pair of silver centers at each vertex.

The vertices of the structure were observed to adopt a new mode of coordination. The two $\mathrm{Ag}^{\mathrm{I}}$ cations at each vertex are coordinated by three distinct naphthyridine-imine arms from different ligands. Two of the arms bridge between $\mathrm{Ag}^{\mathrm{I}}$ centers, using all three $\mathrm{N}$-donors. The third naphthyridine-imine arm only coordinates to the outermost $\mathrm{Ag}^{\mathrm{I}}$ center via two of its $\mathrm{N}$ donors (Figure 2a). The bidentate bridging mode of the napthyridines forces the $\mathrm{Ag}^{\mathrm{I}}$ centers into close proximity, with Ag...Ag distances of $2.816(2)-2.861$ (3) A, within the range reported for other naphthyridine-bridged silver complexes..$^{30,31}$ All $\mathrm{Ag}^{\mathrm{I}}$ centers are coordinated by four nitrogen donors, with Ag-N bond lengths ranging from 2.227(5) - 2.520(7) Å. 
(a)

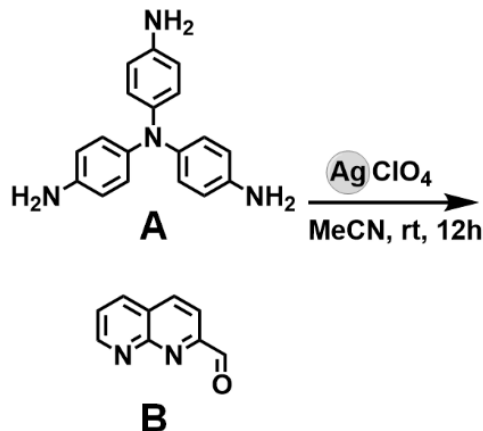

(b)

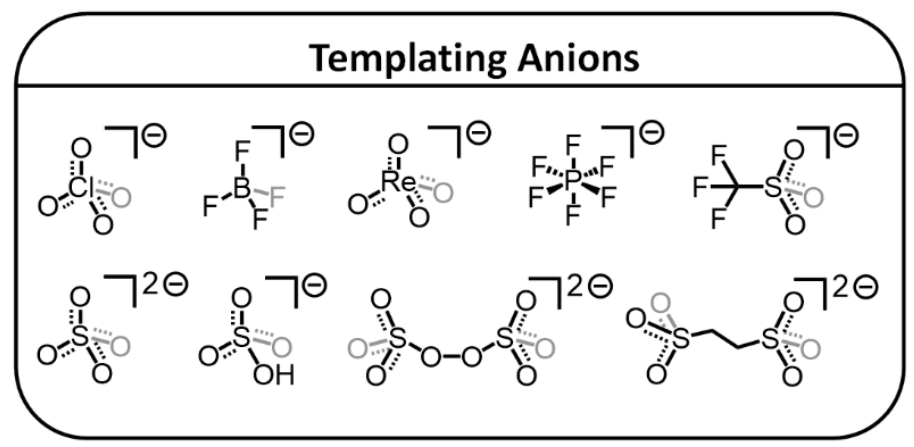

(c)

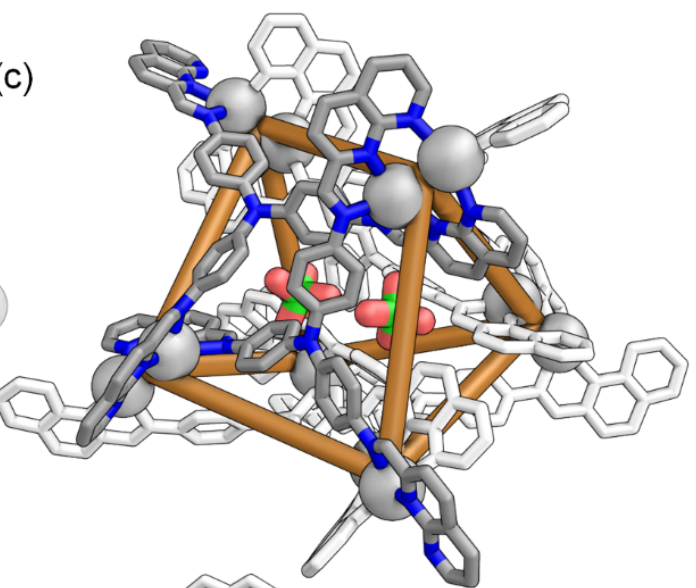

(d)

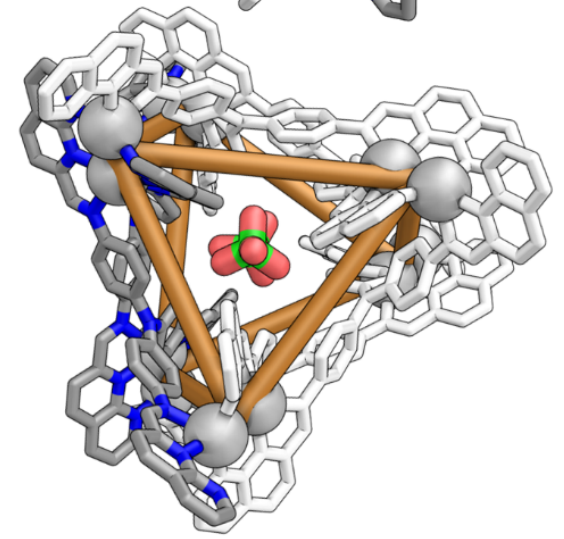

Figure 1. (a). Synthesis of $\mathrm{Ag}_{12}^{\mathrm{I}} \mathrm{L}_{6}$ trigonal prism $\mathbf{1}$ from tris(4-aminophenyl)amine A, 2-formyl-1,8-naphthyridine $\mathbf{B}$ and silver(I) perchlorate. (b) The assembly of $\mathbf{1}$ requires an appropriate template anion. (c) X-ray crystal structure of $\left(\mathrm{ClO}_{4}^{-}\right)_{2} \subset \mathbf{1}$ with the two templating anions included. One pair of ligands is shown in gray to highlight the desymmetrization of the ligand arms. (d) Topdown view depicting the central tubular void of $\left(\mathrm{ClO}_{4}^{-}\right)_{2} \subset \mathbf{1}$. Disorder, non-included anions and solvent molecules have been omitted for clarity.

The two triangular faces of the trigonal prism, as defined by the locations of the centroids of the disilver centers of each vertex, are twisted by $30 \pm 1^{\circ}$ with respect to each other. Two tritopic ligands define each rectangular face of the prism, each bridging between three vertices (Figure 1). Two naphthyridine-imine arms of each ligand connect vertices belonging to the same triangular face, while the third arm bridges to a vertex of the opposing triangular face, through the interior of the structure. The connectivity of the structure is thus similar to a $D_{4}$-symmetric $\mathrm{Cd}^{\mathrm{II}}{ }_{8} \mathrm{~L}_{8}$ tetragonal prism with a larger internal cavity and single-metal vertices. ${ }^{8}$ In the present case, the overall architecture has $D_{3}$ symmetry, as well as a much smaller internal cavity.

The three arms of each tritopic ligand thus experience different environments within the overall structure. Further analysis by COSY and NOESY NMR, both $1 \mathrm{D}$ and $2 \mathrm{D}$, allowed us to unambiguously assign each of the proton environments in solution. All solution-state structural characterization data for $\mathbf{1}$ were consistent with the crystal structure (see SI Section 3).

The crystal structure revealed that the triangular prism bound a pair of $\mathrm{ClO}_{4}{ }^{-}$anions within its elongated cavity. Both encapsulated anions benefit from non-classical hydrogen bonding interactions with internally directed protons of the cage, with $\mathrm{CH}$... anion distances in the range 2.4-2.7 $\AA$. Several other $\mathrm{ClO}_{4}{ }^{-}$anions were found to associate with the periphery of the cage. From this, we inferred anions may play a crucial role in templating the formation of this architecture.
A series of experiments was carried out to further probe the scope of anion templation. Silver bis(trifluoromethanesulfonyl)imide $\left(\mathrm{AgNTf}_{2}\right)$ was used as the silver(I) source in all cases. Following treatment of this salt with subcomponents A and $\mathbf{B}$, it was found that no well-defined structure formed in the absence of a competent template ion (Figure $\mathrm{S}_{5} 8$ ), even after heating the mixture to $60^{\circ} \mathrm{C}$ in an inert atmosphere for 3 days. Molecular modelling, starting from the crystal structure of $\left(\mathrm{ClO}_{4}^{-}\right)_{2} \subset \mathrm{1}$, suggested that the cavity is too small to accommodate $\mathrm{NTf}_{2}{ }^{-}$anions.

Templation of $\left(\mathbf{X}^{-}\right)_{2} \subset \mathbf{1}$ occurred following the addition of two equivalents of trifluoromethanesulfonate (OTf ${ }^{-}$), tetrafluoroborate $\left(\mathrm{BF}_{4}^{-}\right)$, perrhenate $\left(\mathrm{ReO}_{4}^{-}\right)$, hexafluorophosphate $\left(\mathrm{PF}_{6}{ }^{-}\right), \mathrm{ClO}_{4}^{-}$, sulfate $\left(\mathrm{SO}_{4}{ }^{2-}\right)$ and bisulfate $\left(\mathrm{HSO}_{4}^{-}\right)$to the untemplated mixture of A, B, and $\mathrm{AgNTf}_{2}$ (SI Section 4). Cage $\left(\mathrm{X}^{-}\right)_{2} \subset \mathbf{1}$ also formed directly when $\mathrm{AgPF}_{6}, \mathrm{AgClO}_{4}$ or $\mathrm{AgBF}_{4}$ were used as the silver(I) source. $\mathrm{AgReO}_{4}$ and $\mathrm{Ag}_{2} \mathrm{SO}_{4}$ were not sufficiently soluble in acetonitrile to allow for the reaction to proceed.

The diffusion of diethyl ether into a solution of $\left(\text { OTf }^{-}\right)_{2} \subset$ 1 containing excess $\mathrm{TBAPF}_{6}$ furnished crystals of sufficient quality for analysis by $\mathrm{X}$-ray diffraction, confirming formation of a $\mathrm{Ag}_{12}^{\mathrm{I}} \mathrm{L}_{6}$ cage isostructural to $\left(\mathrm{ClO}_{4}^{-}\right)_{2} \subset \mathbf{1}$. A clearly-resolved hexafluorophosphate $\left(\mathrm{PF}_{6}{ }^{-}\right)$anion was observed in one internal site, while the second site contained a disordered mixture of OTf ${ }^{-}$and $\mathrm{PF}_{6}{ }^{-}$(65\%/35\% occupancy respectively, see SI Section 8). 

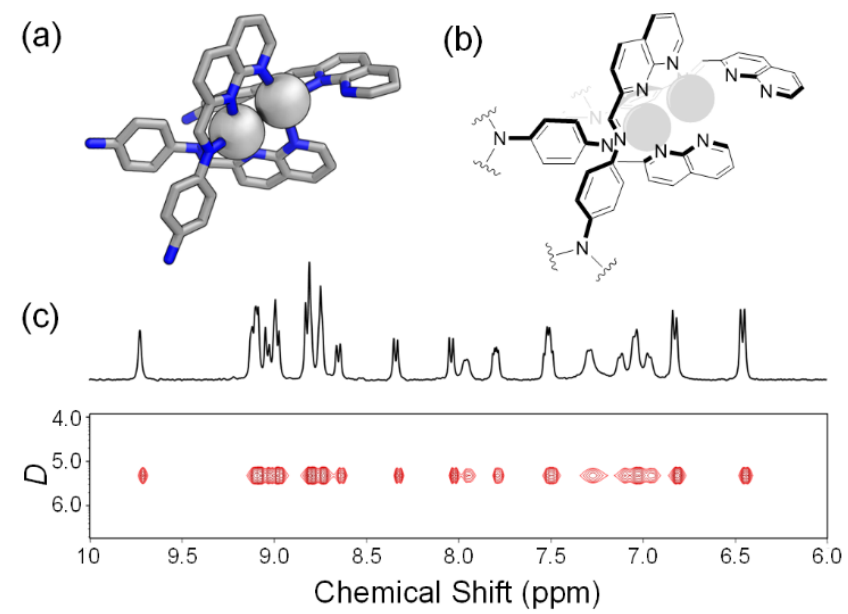

Figure 2. (a) One vertex of $\left(\mathbf{C l O}_{4}^{-}\right)_{2} \subset \mathbf{~ 1}$. (b) Simplified representation of the same vertex. (c) ${ }^{1} \mathrm{H}$ NMR and DOSY NMR spectra (40o $\left.\mathrm{MHz}, 298 \mathrm{~K}, \mathrm{CD}_{3} \mathrm{CN}\right)$ of $\left(\mathrm{ClO}_{4}^{-}\right)_{2} \subset \mathbf{1}$ showing threefold desymmetrization of the cage ligands. The units of $D$ are $10^{-6} \mathrm{~cm}^{2} \mathrm{~s}^{-1}$.

Crystals of $\left(\mathrm{HSO}_{4}^{-}\right)_{2} \subset \mathbf{1}$ formed following the diffusion of $\mathrm{iPr}_{2} \mathrm{O}$ into a concentrated $\mathrm{MeCN}$ solution, and the structure was analysed by single-crystal X-ray diffraction (Figure 3a). The distance between the two encapsulated anions was found to be 4.150 (2) $\AA$, as measured between the two sulfur atoms. This value is similar to the 4.112(1) $\AA$ distance observed by Flood and co-workers, where a pair of $\mathrm{HSO}_{4}{ }^{-}$anions is stabilised by two cyanostar macrocycles. ${ }^{39,40}$ In the case of $\left(\mathrm{ClO}_{4}^{-}\right)_{2}$ $\subset \mathrm{1}$, the $\mathrm{Cl} \cdots \mathrm{Cl}$ distance was found to be $4.88(2) \AA$ (Figure $3 \mathrm{~b}$ ). These results suggest that hydrogen bonding between the two $\mathrm{HSO}_{4}{ }^{-}$anions within the cage cavity, ${ }^{41}$ coupled with interactions between the internally directed protons of the cage and the $\mathrm{HSO}_{4}^{-}$, facilitates close proximity between bisulfate anions.

Noting that each crystal structure obtained contained two bound anions, we next explored whether two anions were required to template the framework of $\mathbf{1}$ in solution. Titration of two equivalents of $\mathrm{TBAHSO}_{4}$ into an untemplated mixture of $\mathbf{A}, \mathbf{B}$, and $\mathrm{AgNTf}_{2}$ revealed complete formation of $\left(\mathrm{HSO}_{4}^{-}\right)_{2} \mathrm{C}$ 1. Addition of further $\mathrm{HSO}_{4}^{-}$led to no appreciable changes (Figure $\mathrm{S}_{5} 8$ ). This result, coupled with the crystallographic evidence, suggested that $\mathbf{1}$ hosts two anions within its central void in solution.

Having observed these supramolecular interactions holding anions in close proximity within $\mathbf{1}$, we questioned whether linear, covalently-linked dianions could also serve as guests and templates for this host. There are few reported examples of such dianions bound inside cage structures. ${ }^{42,43}$ Addition of sodium 1,2-ethanedisulfonate (EDS ${ }^{2-}$ ) was found to lead to formation of the templated cage. Crystallisation by diffusion of $\mathrm{iPr}_{2} \mathrm{O}$ into an $\mathrm{MeCN}$ solution of $\left(\mathbf{E D S}^{\mathbf{2}}\right) \subset \mathbf{1}$, followed by Xray analysis, unambiguously confirmed the formation of a 1:1 host guest complex (Figure 3d), as opposed to the 2:1 complexes described above. (a)

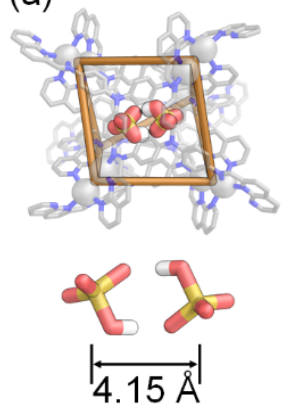

(d)

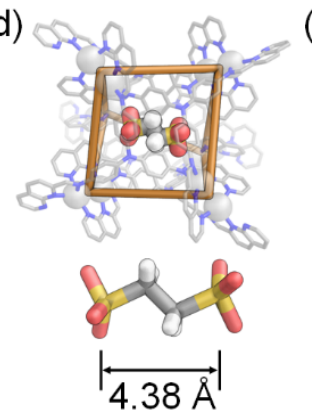

(b)

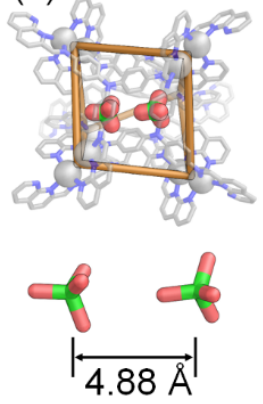

(c)

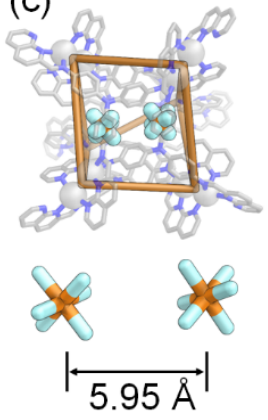

(e)

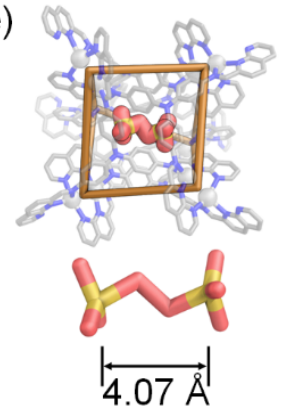

Figure 3. X-ray crystal structures of: (a) $\left(\mathrm{HSO}_{4}^{-}\right)_{2} \subset \mathbf{1}$, (b) $\left(\mathrm{ClO}_{4}^{-}\right)_{2} \subset \mathbf{1},(\mathrm{c})\left(\mathrm{PF}_{6}{ }^{-}\right)_{2} \subset \mathbf{1},(\mathrm{d})\left(\mathrm{EDS}^{2-}\right) \subset \mathrm{I}$ and $(\mathrm{e})\left(\mathrm{S}_{2} \mathrm{O}_{8}{ }^{2-}\right) \subset$ 1 with side-views of the isolated anionic templates.

We also found that the addition of potassium persulfate $\left(\mathrm{S}_{2} \mathrm{O}_{8}{ }^{2-}\right)$, which is known to oxidize $\mathrm{Ag}^{\mathrm{I}}$ to $\mathrm{Ag}^{\mathrm{II}}$ in MeCN solution, ${ }^{44}$ led to the formation of cage $\left(\mathbf{S}_{2} \mathrm{O}_{8}{ }^{2-}\right) \subset \mathbf{1}$. Diffusion of iPr ${ }_{2} \mathrm{O}$ into a solution of $\left(\mathbf{S}_{\mathbf{2}} \mathbf{O}_{\mathbf{8}}{ }^{2-}\right) \subset \mathbf{1}$ in $\mathrm{MeCN}$ produced X-ray quality crystals, which revealed a single $\mathrm{S}_{2} \mathrm{O}_{8}{ }^{2-}$ anion bound in the center of the cage's cavity (Figure 3e). A sulfur-sulfur distance of 4.070 (3) A was measured, shorter than that of the hydrogen-bonded $\mathrm{HSO}_{4}^{-}$dimer. Over the course of 27 days, changes in the ${ }^{1} \mathrm{H}$ NMR spectrum of $\left(\mathbf{S}_{\mathbf{2}} \mathbf{O}_{\mathbf{8}}{ }^{2-}\right) \subset \mathbf{1}$ were observed, consistent with the formation of a new host-guest complex. We thus inferred that the $\mathrm{S}_{2} \mathrm{O}_{8}{ }^{2-}$ was ultimately reduced to other anionic species, which also templated the prism. The ${ }^{1} \mathrm{H}$ NMR spectra of the resulting host-guest species did not match those templated solely by $\mathrm{SO}_{4}{ }^{2-}$ or $\mathrm{HSO}_{4}{ }^{-}$(see SI Section 6).

The shape and size of cage $\mathbf{1}$ was observed to adapt to accommodate the different guest anions, as evidenced in the crystallographic data. The volumes of these anions vary from $53 \AA^{3}$ (for $\mathrm{BF}_{4}^{-}$) to $85 \AA^{3}$ (for $\mathrm{OTf}^{-}$). ${ }^{4}$ Measuring between the centroids of the disilver vertices, significant variations in the conformation of the cage were noted, depending on the guest. While the length of the cage did not vary $(<1 \%$ change), the apertures at the ends of the cage were found to contract by up to $12 \pm 2 \%\left(66.9 \pm 0.3 \AA^{2}\right.$ for $\left(\right.$ EDS $\left.^{2-}\right) \subset 1$ to $76.3 \pm 0.5 \AA^{2}$ for $\left(\mathbf{O T f}^{-} / \mathbf{P F}_{6}{ }^{-}\right)_{2} \subset \mathbf{1}$, see SI Section 9 for details).

The twist angle between the two triangular faces of the prism was also found to vary. With a twist angle of $o^{\circ}$ defining a trigonal prism and $60^{\circ}$ defining a trigonal antiprism, 1 varied between $27.5 \pm 1.0^{\circ}\left(\right.$ for $\left(\mathbf{S}_{\mathbf{2}} \mathbf{O}_{\mathbf{8}}{ }^{2-}\right) \subset \mathbf{1}$ ) and $31 \pm 0.9^{\circ}$ (for (OTf $\left.\left.-/ \mathbf{P F}_{6}{ }^{-}\right)_{2} \subset \mathbf{1}\right)$. These twist angles indicate that the geometry of $\mathbf{1}$ is approximately halfway between an idealized trigonal prism and antiprism.

These changes in the structure of $\mathbf{1}$ are attributed to two factors - structural tuning of $\mathbf{1}$ to maximize favorable interactions with the internalized anions, and crystal packing effects. Smaller anions led to a contraction of the apertures of the 
cage, whereas larger anions required the cage to expand to accommodate them. A greater contraction of the triangular apertures corresponds to a greater distortion of the twist angle from that of an ideal prism.

We have thus demonstrated the formation of a desymmetrized trigonal prismatic cage from bimetallic motifs using subcomponent self-assembly. The use of 2-formyl-1,8-naphthyridine allowed the formation of the disilver corners of cage $\mathbf{1}$, permitting access to this new structure type. The self-assembly process was template-driven, with either two mono-anions, or an elongated dianion, occupying the central, tubular cavity defined by the cage. The cage flexed and adapted in order to accommodate a broad range of anionic species, including strong oxidants. Further work will look to explore this system in aqueous media and examine the potential uses of its unusual binding pocket. New structures and structure types may also become accessible through the use of other subcomponents that contain spatially close, but non-chelating, binding sites for bimetallic motifs at the vertices of polyhedra.

\section{ASSOCIATED CONTENT}

\section{Supporting Information}

The Supporting Information is available free of charge on the ACS Publications website at DOI: xxxxxxxx. Detailed descriptions of synthetic procedures; characterization of new compounds; spectroscopic data (PDF).

X-ray data for $\left(\mathbf{O T f}^{-} / \mathbf{P F}_{6}{ }^{-}\right)_{2} \subset \mathbf{1}(C C D C$ 1913634)

$\mathrm{X}$-ray data for $\left(\mathrm{ClO}_{4}^{-}\right)_{2} \subset \mathbf{1}(\mathrm{CCDC} 1913631)$

$\mathrm{X}$-ray data for $\left(\mathrm{HSO}_{4}^{-}\right)_{2} \subset \mathbf{1}(\mathrm{CCDC}$ 1913633)

$\mathrm{X}$-ray data for $\left(\mathbf{E D S}^{2-}\right) \subset \mathbf{1}(\mathrm{CCDC} 1913632)$

$\mathrm{X}$-ray data for $\left(\mathbf{S}_{\mathbf{2}} \mathbf{O}_{\mathbf{8}}{ }^{2-}\right) \subset \mathbf{1}(\mathrm{CCDC}$ 1913635)

\section{AUTHOR INFORMATION}

\section{Corresponding Author}

*jrn34@cam.ac.uk

\section{ORCID}

John P. Carpenter: oooo-ooo2-4341-2887

Charlie T. McTernan: oooo-0oo3-1359-0663

Tanya K. Ronson: oooo-0oo2-6917-3685

Jonathan R. Nitschke: oooo-0oo2-4060-5122

\section{Author Contributions}

$\ddagger$ J.P.C. and C.T.M. contributed equally.

\section{Notes}

The authors declare no competing financial interests.

\section{ACKNOWLEDGMENT}

This work was supported by the European Research Council (695009) and the UK Engineering and Physical Sciences Research Council (EPSRC, EP/Po27067/1). We thank the EPSRC National Mass Spectrometry Centre (Swansea, UK) for high resolution mass spectrometry and Diamond Light Source (UK) for synchrotron beamtime on I19 (MT15768). JPC thanks the European Union's Horizon 2020 research and innovation program, Marie Sklodowska-Curie Grant (642192). CTM thanks the Leverhulme and Isaac Newton Trusts, and Sidney Sussex College, Cambridge for Fellowship support.

\section{REFERENCES}

(1) Chand, D. K.; Biradha, K.; Fujita, M.; Sakamoto, S.; Yamaguchi, K. A Molecular Sphere of Octahedral Symmetry. Chem. Commun. 2002, 2486-2487.

(2) Freye, S.; Michel, R.; Stalke, D.; Pawliczek, M.; Frauendorf, H.; Clever, G. H. Template Control over Dimerization and Guest Selectivity of Interpenetrated Coordination Cages. J. Am. Chem. Soc. 2013, 135, 8476-8479.

(3) Yazaki, K.; Sei, Y.; Akita, M.; Yoshizawa, M. A Polyaromatic Molecular Tube That Binds Long Hydrocarbons with High Selectivity. Nat. Commun. 2014, 5, 5179.

(4) Argent, S. P.; Adams, H.; Riis-Johannessen, T.; Jeffery, J. C.; Harding, L. P.; Ward, M. D. High-Nuclearity Homoleptic and Heteroleptic Coordination Cages Based on Tetra-Capped Truncated Tetrahedral and Cuboctahedral Metal Frameworks. J. Am. Chem. Soc. 20o6, 128, 72-73.

(5) Riddell, I. A.; Hristova, Y. R.; Clegg, J. K.; Wood, C. S.; Breiner, B.; Nitschke, J. R. Five Discrete Multinuclear MetalOrganic Assemblies from One Ligand: Deciphering the Effects of Different Templates. J. Am. Chem. Soc. 2013, 135, 2723-2733.

(6) Jansze, S. M.; Wise, M. D.; Vologzhanina, A. V.; Scopelliti, R.; Severin, K. $\mathrm{Pd}_{2}{ }_{2} \mathrm{~L}_{4}$-Type Coordination Cages up to Three Nanometers in Size. Chem. Sci. 2017, 8, 1901-19o8.

(7) Sun, Q.-F.; Sato, S.; Fujita, M. An $\mathrm{M}_{18} \mathrm{~L}_{24}$ Stellated Cuboctahedron through Post-Stellation of an $\mathrm{M}_{12} \mathrm{~L}_{24}$ Core. Nat. Chem. 2012, 4, 330-333.

(8) Suzuki, K.; Sato, S.; Fujita, M. Template Synthesis of Precisely Monodisperse Silica Nanoparticles within Self-Assembled Organometallic Spheres. Nat. Chem. 2o10, 2, 25-29.

(9) Yu, F.; Poole, D.; Mathew, S.; Yan, N.; Hessels, J.; Orth, N.; Ivanović-Burmazović, I.; Reek, J. N. H. Control over Electrochemical Water Oxidation Catalysis by Preorganization of Molecular Ruthenium Catalysts in Self-Assembled Nanospheres. Angew. Chem., Int. Ed. 2018, 57, 11247-11251.

(10) Zhang, D.; Ronson, T. K.; Mosquera, J.; Martinez, A.; Guy, L.; Nitschke, J. R. Anion Binding in Water Drives Structural Adaptation in an Azaphosphatrane-Functionalized $\mathrm{Fe}_{4}{ }_{4} \mathrm{~L}_{4}$ Tetrahedron. J. Am. Chem. Soc. 2o17, 139, 6574-6577.

(11) Custelcean, R.; Bonnesen, P. V.; Duncan, N. C.; Zhang, X.; Watson, L. A.; Van Berkel, G.; Parson, W. B.; Hay, B. P. Urea-Functionalised $\mathrm{M}_{4} \mathrm{~L}_{6}$ Cage Receptors: Anion-Templated Self-Assembly and Selective Guest Exchange in Aqueous Solutions. J. Am. Chem. Soc. 2012, 134, 8525-8534.

(12) Custelcean, R.; Bonnesen, P. V.; Roach, B. D.; Duncan, N. C. Ion-pair triple helicates and mesocates self-assembled from ditopic 2,2'-bipyridine-bis(urea) ligands and $\mathrm{Ni}(\mathrm{II})$ or Fe(II) sulfate salts. Chem. Commun. 2012, 48, 7438-7440.

(13) Albrecht, M.; Isaak, E.; Baumert, M.; Gossen, V.; Raabe, G.; Fröhlich, R. "Induced Fit" in Chiral Recognition: Epimerization upon Dimerization in the Hierarchical Self-Assembly of Helicate-Type Titanium(IV) Complexes. Angew. Chem., Int. Ed. 2011, 50, 2850-2853.

(14) Mal, P.; Breiner, B.; Rissanen, K.; Nitschke, J. R. White Phosphorus Is Air-Stable within a Self-Assembled Tetrahedral Capsule. Science 2009, 324, 1697-1699.

(15) Cullen, W.; Misuraca, M. C.; Hunter, C. A.; Williams, N. H.; Ward, M. D. Highly Efficient Catalysis of the Kemp Elimination in the Cavity of a Cubic Coordination Cage. Nat. Chem. 2016, 8, 231-236.

(16) Murase, T.; Nishijima, Y.; Fujita, M. Cage-Catalyzed Knoevenagel Condensation under Neutral Conditions in Water. J. Am. Chem. Soc. 2012, 134, 162-164. 
(17) Rizzuto, F. J.; Pröhm, P.; Plajer, A. J.; Greenfield, J. L.; Nitschke, J. R. Hydrogen-Bond-Assisted Symmetry Breaking in a Network of Chiral Metal-Organic Assemblies. J. Am. Chem. Soc. 2019, 141, 1707-1715.

(18) Song, B.; Kandapal, S.; Gu, J.; Zhang, K.; Reese, A.; Ying, Y.; Wang, L.; Wang, H.; Li, Y.; Wang, M.; Lu, S.; Hao, X.-Q.; Li, X.; Xu, B.; Li, X. Self-Assembly of Polycyclic Supramolecules Using Linear Metal-Organic Ligands. Nat. Commun. 2018, 9, 4575 .

(19) Hasenknopf, B.; Lehn, J.-M.; Boumediene, N.; DupontGervais, A.; Van Dorsselaer, A.; Kneisel, B; Fenske, D. Self-Assembly of Tetra- and Hexanuclear Circular Helicates. J. Am. Chem. Soc. 1997, 119, 10956-10962.

(20) Hasenknopf, B.; Lehn, J.-M.; Kneisel, B. O.; Baum, G.; Fenske, D. Self-Assembly of a Circular Double Helicate. Angew. Chem., Int. Ed. 1996, 35, 1838-1840.

(21) Hasenknopf, B.; Lehn, J.-M.; Boumediene, N.; Leize, E.; Van Dorsselaer, A. Kinetic and Thermodynamic Control in Self-Assembly: Sequential Formation of Linear and Circular Helicates. Angew. Chem., Int. Ed. 1998, 37, 3265-3268.

(22) Cullen, W.; Metherell, A. J.; Wragg, A. B.; Taylor, C. G. P.; Williams, N. H.; Ward, M. D. Catalysis in a Cationic Coordination Cage Using a Cavity-Bound Guest and SurfaceBound Anions: Inhibition, Activation, and Autocatalysis. J. Am. Chem. Soc. 2018, 140, 2821-2828.

(23) Tidmarsh, I. S.; Faust, T. B.; Adams, H.; Harding, L. P.; Russo, L.; Clegg, W.; Ward, M. D. Octanuclear Cubic Coordination Cages. J. Am. Chem. Soc. 20o8, 130, 15167-15175.

(24) Ayme, J.-F.; Beves, J. E.; Leigh, D. A.; McBurney, R. T.; Rissanen, K.; Schultz, D. A Synthetic Molecular Pentafoil Knot. Nat. Chem. 2012, 4, 15-20.

(25) Danon, J. J.; Krüger, A.; Leigh, D. A.; Lemonnier, J.-F.; Stephens, A. J.; Vitorica-Yrezabal, I. J.; Woltering, S. L. Braiding a Molecular Knot with Eight Crossings. Science 2017, 355, 159-162.

(26) Buchard, A.; Kember, M. R.; Sandeman, K. G.; Williams, C. K. A Bimetallic Iron(III) Catalyst for $\mathrm{CO}_{2} /$ Epoxide Coupling. Chem. Commun. 2011, 47, 212-214.

(27) Desai, S. P.; Ye, J.; Zheng, J.; Ferrandon, M. S.; Webber, T. E.; Platero-Prats, A. E.; Duan, J.; Garcia-Holley, P.; Camaioni, D. M.; Chapman, K. W.; Delferro, M.; Farha, O. K.; Fulton J. L.; Gagliardi L.; Lercher J. A.; Penn R. L.; Stein A.; Lu C. C. Well-Defined Rhodium-Gallium Catalytic Sites in a Metal-Organic Framework: Promoter-Controlled Selectivity in Alkyne Semihydrogenation to E-Alkenes. J. Am. Chem. Soc. 2018, 140, 15309-15318.

(28) Artem'ev, A. V.; Bagryanskaya, I. Y.; Doronina, E. P.; Tolstoy, P. M.; Gushchin, A. L.; Rakhmanova, M. I.; Ivanov, A. Y.; Suturina, A. O. A New Family of Clusters Containing a Silver-Centered Tetracapped $\left[\mathrm{Ag} @ \mathrm{Ag}_{4}\left(\mu_{3}-\mathrm{P}\right)_{4}\right]$ Tetrahedron, Inscribed within a $\mathrm{N}_{12}$ Icosahedron. Dalton. Trans. 2017, 46, $12425^{-12429 .}$

(29) Schenck, T. G.; Downes, J. M.; C Milne, C. R.; Mackenzie, P. B.; Boucher, H.; Whelan, J.; Bosnich, B. Bimetallic Reactivity. Synthesis of Bimetallic Complexes Containing a Bis(Phosphino)Pyrazole Ligand. Inorg. Chem. 1985, 24, 23342337.

(30) Sowa, T.; Kawamura, T.; Shida, T.; Yonezawa, T. Electronic Structure of the Rhodium-Rhodium Bond in Dirhodium Tetracarboxylates by a Study of Electronic Spectra of Neutral Molecules and Their Cation Radicals. Inorg. Chem. 1983, 22, 56-61.
(31) Bera, J. K.; Sadhukhan, N.; Majumdar, M. 1,8-Naphthyridine Revisited: Applications in Dimetal Chemistry. Eur. J. Inorg. Chem. 2009, 27, 4023-4038.

(32) Giordana, A.; Priola, E.; Bonometti, E.; Benzi, P.; Operti, L.; Diana, E. Structural and Spectroscopic Study of the Asymmetric 2-(2 -Pyridyl)-1,8-Naphthyridine Ligand with ClosedShell Metals. Polyhedron 2017, 138, 239-248.

(33) Dong, Y.-B.; Geng, Y.; Ma, J.-P.; Huang, R.-Q. Organometallic Silver(I) Supramolecular Complexes Generated from Multidentate Furan-Containing Symmetric and Unsymmetric Fulvene Ligands and Silver(I) Salts. Inorg. Chem. 2005, 44, 1693-1703.

(34) Yue, N. L. S.; Jennings, M. C.; Puddephatt, R. J. Disilver(I) Macrocycles: Variation of Cavity Size with Anion Binding. Inorg. Chem. 2005, 44, 1125-1131.

(35) Beauchamp, D. A.; Loeb, S. J. Molecular Squares, Rectangles and Infinite Helical Chains Utilising the Simple 'Corner' Ligand 4-(2-Pyridyl)-Pyrimidine. Chem. Commun. 2002, 2484-2485

(36) Wiley, C. A.; Holloway, L. R.; Miller, T. F.; Lyon, Y.; Julian, R. R.; Hooley, R. J. Electronic Effects on Narcissistic SelfSorting in Multicomponent Self-Assembly of Fe-Iminopyridine Meso-Helicates. Inorg. Chem. 2016, 55, 9805-9815.

(37) Ronson, T. K.; Zarra, S.; Black, S. P.; Nitschke, J. R. Metal-organic Container Molecules through Subcomponent Self-Assembly. Chem. Commun. 2013, 49, 2476-249o.

(38) Mosquera, J.; Ronson, T. K.; Nitschke, J. Subcomponent Flexibility Enables Conversion between $\mathrm{D}_{4}$-Symmetric $\mathrm{Cd}^{\mathrm{II}}{ }_{8} \mathrm{~L}_{8}$ and T-Symmetric $\mathrm{Cd}^{\mathrm{II}}{ }_{4} \mathrm{~L}_{4}$ Assemblies. J. Am. Chem. Soc. 2016, 138, 1812-1815.

(39) Fatila, E. M.; Twum, E. B.; Karty, J. A.; Flood, A. H. Ion Pairing and Co-Facial Stacking Drive High-Fidelity Bisulfate Assembly with Cyanostar Macrocyclic Hosts. Chem. Eur. J. 2017, 23, 10652-10662.

(40) Dobscha, J. R.; Debnath, S.; Fadler, R. E.; Fatila, E. M.; Pink, M.; Raghavachari, K.; Flood, A. H. Host-Host Interactions Control Self-Assembly and Switching of Triple and Double Decker Stacks of Tricarbazole Macrocycles Co-Assembled with Anti-Electrostatic Bisulfate Dimers. Chem. Eur. J. 2018, 24, 9841-9852.

(41) Substantial disorder of the oxygen atoms of the encapsulated $\mathrm{HSO}_{4}{ }^{-}$anions precluded accurate resolution of the hydrogen atom of these anions. However the observed distance between the disordered $\mathrm{HSO}_{4}{ }^{-}$anions is consistent with the presence of a hydrogen bonded dimer.

(42) Bravin, C.; Guidetti, A.; Licini, G.; Zonta, C. Supramolecular Cages as Differential Sensors for Dicarboxylate Anions: Guest Length Sensing Using Principal Component Analysis of ESI-MS and ${ }^{~} \mathrm{H}-\mathrm{NMR}$ Raw Data. Chem. Sci. 2019, 10, 3523-3528.

(43) Clever, G. H.; Kawamura, W.; Shionoya, M. Encapsulation versus Aggregation of Metal-Organic Cages Controlled by Guest Size Variation. Inorg. Chem. 2o11, 50, 4689-4691.

(44) Minisci, F.; Citterio, A.; Giordano, C. Electron-Transfer Processes: Peroxydisulfate, a Useful and Versatile Reagent in Organic Chemistry. Acc. Chem. Res. 1983, 16, 27-32. 

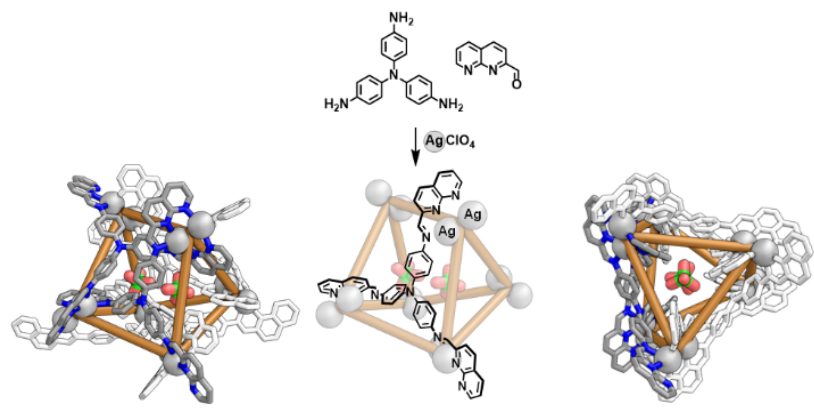

For use as a TOC only 